\title{
¿ES POSIBLE LA ESTÉTICA LITERARIA? (Nota sobre la concepción de Heidegger)
}

LUIS BELTRÁN ALMERÍA

Universidad de Zaragoza

\begin{abstract}
Quizá no se haya valorado en su justa medida el hecho de que Martin Heidegger asumiera la tarea de clarificar los conceptos esenciales de la estética, en general, y de la estética literaria, en particular. Desde un punto de vista académico, nada tiene de extraño que el magno proyecto de estudio del ser en el tiempo aborde las cuestiones relacionadas con la estética. Pero si se consideran los problemas de la estética (y de la estética literaria, en particular) desde el punto de vista de las corrientes hegemónicas del pensamiento moderno, veremos que, salvo unos tímidos intentos más o menos inconexos entre sí, la era moderna ha preferido sostener la imposibilidad de la estética. Esa imposibilidad ha sido teorizada por los filósofos y practicada por los filólogos, que han tendido a comprender el objeto literario como simple idea o mera cosa (el texto). Uno de los aspectos que más claramente revelan tal negación de la dimensión estética de la obra de arte o de la obra literaria es la reducción de la obra a una unión de forma y contenido. Esta fórmula sitúa el objeto estético, literario o plástico, en el mismo plano que las ideas: son las ideas los entes que se distinguen por tener una forma (variable) y un contenido (estable).

Sin embargo, el punto de partida de Heidegger no es la crítica del pensamiento orgánico moderno sino, más bien, la crítica de una concepción metafísica de lo ente. Esta es la razón de que se plantee delimitar el objeto estético de la mera cosa, esto es, de un ente dotado de materia y forma, la fórmula del ente cósico. Heidegger, en su ensayo «El origen de la obra de arte», empieza por preguntarse por lo que hay de mera cosa en el objeto estético y tras una larga indagación llega a la conclusión de que, aun habiendo algo cósico en el objeto estético, este no puede ser reducido a mera cosa y, preguntándose por él como cosa, no se llega a ninguna parte. El propio Heidegger insiste en la importancia de esta investigación, pese a que le lleva un elevado número de páginas - unas 50 - para llegar a una simple conclusión negativa.
\end{abstract}

Rlit, LXVII, 133 (2005), 167-180 
Lo importante es que el propio Heidegger reivindica la concepción del objeto estético como acontecimiento $(1952,88)$. Para ser más respetuoso con el texto heideggereano es la noción de verdad lo que es concebido como acontecimiento, como desocultación ( $\dot{\alpha} \lambda \eta \theta \varepsilon i ́ \alpha)$. Pero de esa concepción de la verdad como desocultación, y no como corrección, se sigue que el ser de la obra consiste precisamente en fijar la verdad en la forma artística $(1952,100)$. Esta «fijación» entre verdad y estética tiene un innegable sello platónico. Pero no es esto lo que interesa ahora. Las preguntas que se debe formular son, de momento, dos: ¿qué significa la noción de verdad como desocultación? y ¿por qué el ser de la obra consiste precisamente en fijar el acontecimiento de la desocultación en la forma artística?

Contestar la primera pregunta - ¿qué es verdad como desocultación?obliga a un esfuerzo que no procede aquí y ahora. Bastará con que formule algunas observaciones acerca de este concepto. Verdad-desocultaciónacontecimiento se opone a una concepción de la verdad como adecuación a un proceso sobrehumano, que la reduce a la mera corrección al dictado de tal proceso. Esta es la concepción del dogmatismo. Operando con esta concepción dogmática de la verdad no podemos aspirar más que a preguntarnos por el ser-cosa de la obra artística y Heidegger ya se ha encargado de poner toda su paciencia en demostrar a cuán poco se llega preguntando por lo cósico de la obra. Acceder a una concepción de la verdad como desocultación o acontecimiento es condición sine qua non para superar la concepción cosificada de la obra. Esa desocultación se produce como un alumbramiento y ocultación del ente. Este proceso doble acontece al poetizar. Todo arte es como dejar acontecer el advenimiento de la verdad del ente y por eso es en esencia Poesía (Dichtung), viene a decir Heidegger.

De esta concepción del arte como verdad-desocultación se deriva la teoría heideggeriana del lenguaje y de la poesía. La concepción heideggeriana del ente lo supone como un elemento complejo dotado de una luz paradójica propia que al iluminarse produce el ocultamiento. Esa iluminación externa no la puede producir otra cosa que el lenguaje. El habla no es sólo una especie de comunicación, la expresión oral y escrita de lo que debe ser comunicado -es decir, el lenguaje no es un simple instrumento. El lenguaje es el generador de la potencia del ente. El ente llega a lo manifiesto gracias al lenguaje, y donde no hay discurso no hay constancia del ente y tampoco de la no-existencia, de lo vacío. El discurso llama al ente a su ser. El discurso arroja la luz al momento en el que el ente llega a lo manifiesto. Ese discurso alumbrador es Poesía (Dichtung). Es el discurso del mundo y de la tierra, y de su lucha. La Poesía - el arte literario, que eso quiere decir ahora esta palabra- es el discurso de la desocultación del ente. Ya F. Schlegel había dicho: el contenido de la Poesía es la Religión, en un lenguaje más críptico que el de Heidegger. 
Lo que la Poesía, como iluminación sobre lo descubierto, hace estallar e inyecta por anticipado en la desgarradura de la forma es lo abierto, al que deja acontecer de manera que ahora estando en medio del ente lleva a éste al alumbramiento y a la armonía $(1952,111)$.

Así que la Poesía es lenguaje esencial y el lenguaje mismo es Poesía en ese sentido esencial. De aquí se deducen tres grandes líneas del pensamiento estético de Heidegger:

1. La relevancia del arte literario, que sitúa este pensamiento en las antípodas de la concepción retórica del arte y la literatura, característica del relativismo radical.

2. El profundo sentido histórico del lenguaje y de la Poesía (Dichtung), que denuncia el historicismo superficial del pensamiento positivista, y

3. La premisa de que la poesía en sentido restringido es la Poesía más originaria en sentido esencial. Esta idea tiene relación íntima con la aceptación de la idea hegeliana de la muerte del arte.

Pero antes de analizar en profundidad los efectos de la concepción heideggeriana de la obra conviene desmenuzar el engranaje del objeto estético, tal cual lo idea el filósofo de Heidelberg. En la contemplación pormenorizada de dicho engranaje encontraremos las claves que nos permitirán explicar después el alcance de las ideas estéticas heideggerianas.

\section{EL OBJETO ESTÉTICO EN HEIDEGGER}

La primera y primordial consecuencia de la comprensión del objeto estético como fijación del acontecimiento de la desocultación en la forma artística es el reconocimiento de todos los elementos o participantes esenciales en esa operación. Y estos participantès esenciales son: el creador, el contemplador, la tierra, el mundo y la forma. Heidegger presta especial atención a tres de ellos: el mundo, la tierra y el contemplador. Hay una doble razón para esta atención. Por un lado son los elementos que el filósofo alemán carga de un contenido más original. Y, paradójicamente, se trata de los elementos más convencionales en la investigación estética moderna: el mundo es lo que tradicionalmente se llama contenido, la tierra es lo que tradicionalmente se llama forma - y que de modo más preciso llamaré material - y el contemplador es el elemento sobre el que ha girado la reflexión estética del siglo $\mathrm{xx}$, a causa del relativismo ideológico dominante y que ha sustituido al autor, que fue el gran eje teórico de la estética decimonónica (por lo menos hasta Croce). El último, la forma estética, no es precisamente nuevo. Posee una amplia tradición en el pensamiento estético premoderno y fue sutilmente analizado por los románticos 
alemanes (F. Schlegel y Novalis, especialmente). No tiene nada que ver con lo que en la teoría literaria y artística cotidianas se ha llamado forma en el siglo XX, que como ya queda dicho, no es sino el material (verbal o plástico).

Fijémonos más detenidamente en el binomio mundo/tierra, que contiene a la vez la mayor originalidad y encubre el elemento más vulgar: la oposición forma/contenido. «Ser obra significa establecer un mundo», «la obra como obra establece un mundo» y «la obra mantiene abierto lo abierto de un mundo.» $\mathrm{Y}$, sobre lo que debemos entender por mundo, dice:

El mundo no es el mero conjunto de cosas existentes contables o incontables, conocidas o desconocidas. Tampoco es el mundo un marco imaginado para encuadrar el conjunto de lo existente. (..) Nunca es el mundo un objeto ante nosotros que se pueda mirar $(1952,74-75)$.

El mundo no es nada de eso, ni marco ni objeto. Es, en cambio, un ámbito, un ámbito sólo accesible al ser humano -ni las piedras ni las plantas, ni los animales lo tienen. La obra da lugar a ese ámbito y eso significa «dejar en libertad lo que de libre tiene lo abierto y ordenado en el conjunto de sus rasgos». «La obra como obra establece un mundo». Más adelante añade unas notas clarificadoras de ese establecimiento del mundo «en el sentido de una erección que consagra y glorifica» $(1952,76)$.

La crítica ha tomado esta oposición tierra/mundo como las dos únicas partes del objeto estético heideggeriano, los dos únicos héroes del combate en el que se funda la verdad. A. de Waelhens (1967, 283-292) se fija en la distinta significación que tiene la palabra mundo en «Von Ursprung des Kunstwerkes» respecto a Sein und Zeit. Y se expresa con una enorme precisión respecto al contenido de la obra de arte:

L'oeuvre d'art est donc le théâtre d'un combat. Elle équilibre le lutte incessante de deux éléments irréconciliables: le monde de l'homme qui, bien que n'étant pas rationnel au sens strict, ne tolère aucune obscurité, et l'élément chtonique qui s'efforce de tout absorber dans sa nuit $(1967,287)$.

Para dar esta visión simplificada de la tensión en la obra de arte De Waelhens ha recurrido a la reducción del objeto estético que pierde su naturaleza de acontecimiento para recobrar su ya tradicional cosificación.

Hay, sin embargo, elementos que facilitan esa visión reductora en el ensayo de Heidegger. En primer lugar, el mismo Heidegger no parece ser muy consciente de la necesidad de romper con la concepción del objeto como asociación de forma y contenido. Esto le hace dar continuamente protagonismo a la pareja mundo/tierra, en detrimento de los demás elementos del objeto. Por supuesto, entre las distintas concepciones de la cosicidad del objeto estético no figura precisamente esa (aunque, como he observado, en puridad no es preciso, pues desde un punto de vista enteramente 
filosófico no es diferenciable de la oposición materia/forma, y sólo lo es desde un punto de vista histórico-crítico). En segundo lugar, la concepción retórica de la literatura, de la que Heidegger - pese a todo- es incapaz de librarse, conduce y alimenta ese protagonismo, que hace oscurecer a los otros integrantes del drama.

Sin embargo, se puede ver numerosas pruebas de la mayor amplitud del escenario heideggeriano. Por ejemplo, cuando proclama:

El establecimiento de un mundo y la hechura de la tierra son dos rasgos esenciales en el ser-obra $(1952,79)$.

«Dos rasgos esenciales», luego hay más, Esos rasgos esenciales forman una unidad, la unidad del combate:

Al establecer la obra un mundo y hacer la tierra, instiga a la lucha (...) El ser-obra de la obra consiste en pelear esta lucha entre el mundo y la tierra $(1952,81)$.

Pero no se debe perder de vista la diferencia que Heidegger establece entre ser-objeto y ser-obra. El ser-obra es la obra creada (natura naturata), es lo cósico de la obra $(1952,91)$. Pero el ser-objeto, la esencia de la obra, pertenece al acontecer de la verdad. Y la relación entre la «obra» (lo cósico) y el objeto estético exige, según Heidegger, que nos preguntemos sobre la verdad y su esencia.

Al llevar el problema estético al nivel de la verdad, Heidegger está haciendo de él un problema interpersonal, un problema entre el artista y el contemplador. Ciertamente esta pareja tiene un papel desigual en la representación heideggeriana del drama estético. R. Magliola (1983, 120 y ss.) ha llamado también la atención sobre esta ausencia a propósito de la sección 32 de Sein und Zeit. Una ausencia como ésta es siempre una deficiencia, aunque en este caso se trate de un vacío en cierta forma rellenable, pues una interpretación fenomenológica de la obra - el acontecimientoexige siempre una concepción intersubjetiva. La contemplación de la obra le preocupa mucho más que su autoría.

Aunque el olvido en que puede caer la obra no es la nada. Es todavía una contemplación que se alimenta de la obra. La contemplación de la obra significa estar dentro de la potencia del ente que acontece en la obra. Pero la estancia dentro de la contemplación es un saber. Sin embargo, el saber no consiste en mero conocer y representarse de algo. Quien verdaderamente sabe del ente, sabe lo que quiere en medio del ente $(1952,104)$.

Al contemplador - a la contemplación - le dedica Heidegger mayor atención que al autor. Es natural. En esto Heidegger se comporta como un hijo de su siglo, que ha preferido el punto de vista del lector (y de la crítica) al del autor - por reacción al siglo XIX que abusó del papel del autor. Es 
esencial comprender el carácter de interioridad que Heidegger atribuye al contemplador. Este es un momento más del objeto estético, un momento imprescindible para que pueda darse el combate tierra/mundo. Desgraciadamente Heidegger extrae muy pocas conclusiones de la naturaleza de la contemplación. Nos dice que es un saber, pero un saber que responde a leyes especiales, no es simple manifestación cognitiva, sino expresión y producto de la obra misma. Ahora bien, ese saber parece algo estático, alojado en el ser-obra de la obra. No parece permitir la concepción heideggeriana del objeto estético un crecimiento de ese objeto a lo largo de los siglos. En otras palabras, la dimensión de la obra de arte, según Heidegger, depende directamente del grado de absorción de su mundo, absorción que sigue irradiando, mediante una luz paradójica, por los siglos venideros. Pero la expresión estética no parece indicarnos que Hamlet, Fausto o Crimen y castigo sean grandes obras de arte porque hayan captado e irradien un momento histórico, una época, un mundo. Mas bien, parece que esas grandes obras sigan creciendo con el paso de los siglos, se enriquecen ante cada nueva época que encuentran en ellas aspectos desconocidos para el propio autor y sus contemporáneos. Este aspecto del crecimiento de la obra a partir de la crítica no existe en el pensamiento de Heidegger. La elección del término contemplación parece indicar claramente el papel pasivo que adjudica al receptor. De ahí también que Heidegger encuentre cierta simetría entre creación y contemplación.

Al ser-creatura de la obra pertenece tan esencialmente la creación como la contemplación (...) Si el arte es el origen de la obra, entonces quiere decirse que hace brotar en su esencia la mutua correspondencia esencial en la obra, de la creación y la contemplación (1952, 109-110).

Incluso se puede afirmar que la misma pasividad que afecta a la contemplación parece reflejarse en la creación. Probablemente por eso no le dedica apenas atención. En su insistencia en la autonomía de la obra - «la obra debe ser abandonada a su puro reposar en sí misma» $(1952,68)$ - la creación pierde valor una vez creada la obra.

Precisamente en el arte grande (...) el artista queda ante la obra como algo indiferente, casi como un conducto a la producción, que se destruye a sí mismo, una vez creada la obra $(1952,68-69)$.

Curiosa paradoja, la concepción de la obra como lucha, como acontecimiento exige actores y, sin embargo, Heidegger, al tiempo que se distancia de la concepción cosificada de la obra, disuelve la dimensión interpersonal -intersubjetiva - de la obra. Les coloca sordinas a sus actores. Una de las consecuencias de la ausencia de una teoría de la autoría en el pensamiento de Heidegger es la resistencia de ese pensamiento a una teoría de los géneros y su proclamación de la Poesía como lenguaje originario. Pero no ha llegado el momento aún de abordar esta cuestión. 
El aspecto que Heidegger desarrolla de la creación es su dimensión de téjne, que le lleva a proclamar que el artista es un tejnite. Con ello no quiere decir que el artista sea un artesano, ni que la confección manual juegue un papel en la creación de la obra. Al contrario, la obra sólo se hace real al llevarse a cabo la creación y depende de ella en su realidad material. Del mismo modo, «la esencia de la creación depende de la esencia de la obra» $(1952,95)$. Hay aquí un cierto eco del Ion platónico. La que en el Ion es una disyuntiva clara -o técnica o inspiración divina-, aquí se resuelve mediante una paradoja que se inclina más por el segundo término de la oposición socrática.

De las dos parejas analizadas hasta aquí, la de los componentes (tierra/ mundo) tiene una hegemonía clara en el pensamiento heideggeriano sobre la de los partícipes (creador y contemplador). El término partícipes no es casual. No se trata de auténticos sujetos, son sólo partes, dotadas de una vida relativa, del objeto estético. Queda por revisar el quinto y definitivo componente del objeto estético: la forma.

La belleza descansa sobre la forma, proclaman las conclusiones de la investigación heideggeriana $(1952,122)$. Nada tiene que ver la noción de Heidegger de forma con el concepto vulgar de forma, que en el pensamiento literario moderno es sinónimo de material (verbal o plástico). La forma es la fijación de la lucha entre el mundo y la tierra.

En la creación de la obra la lucha como desgarradura debe volver a asentarse en la tierra y esta misma debe resaltar y emplearse como lo autoocultante. Pero este uso no gesta la tierra, ni abusa de ella como materia, sino que la pone en libertad, para ella misma $(1952,101)$.

La conforma; le da forma estética, cabría añadir al texto heideggeriano. Es un uso «de la tierra para fijar la verdad en forma» $(1952,101)$. Consciente de que lo que él llama forma puede dar lugar a malentendidos, Heidegger aclara:

Lo que aquí se llama forma debe entenderse por aquella posición y composición en que la obra es en tanto que se expone y se propone $(1952,100)$.

Lo que, sin duda, dice más de su voluntad de clasificar que de sus virtudes analíticas y expresivas. Con esta concepción formal, Heidegger recupera la olvidada herencia de F. Schlegel y Novalis que reivindican el arte como continuum formal que cumple la función de servir de medium de reflexión. Tampoco esto es casual. Una alternativa al pensamiento estético moderno necesariamente ha de apoyarse en el bagaje teórico del círculo romántico de los Schlegel. Las propuestas de ese círculo contradicen la idea escéptica de G. Vattimo (1985, 10), para quien ni el pensamiento describe un desarrollo progresivo a partir del fundamento-origen, ni cabe la posibilidad de una alternativa hipotética basada en una superación del origen- 
fundamento. Sin embargo, esa superación del pensamiento estético moderno no es ni mucho menos completa en el pensamiento de Heidegger. Su dependencia del pensamiento de Hegel actúa como freno de esa superación.

Pero quizá convenga dar un repaso más ordenado a los resultados de esta original concepción del objeto estético. En primer lugar, hay que subrayar que la actitud de Heidegger ante la teoría del arte es una actitud crítica. Su exposición proviene de una toma de distancia frente al pensamiento tradicional. Como dice Vattimo, Nietzsche y Heidegger buscaron una peculiar relación «crítica» con el pensamiento occidental $(1985,10)$. En cualquier caso la propuesta de Heidegger es probablemente menos nihilista de lo que exige el canon posmoderno, a pesar, incluso, de la reivindicación heideggeriana del nihilismo como reducción del ser a valor (de uso, según Vattimo). Sea como sea, lo importante es que la peculiar actitud crítica de Heidegger contiene una paradójica propuesta de futuro, que puede sintetizarse en dos o tres titulares: Poesía, lenguaje primordial; la muerte del arte (o, si se prefiere, atrincheramiento en la estética seria); y, finalmente, la verdad relativa de la belleza. Analizaré a continuación el alcance de cada uno de estos postulados.

\section{POESÍA, LENGUAJE PRIMORDIAL}

La concepción crítica del objeto estético que propone Heidegger le sirve de fundamento para desarrollar, más o menos originalmente, una concepción tópica en la estética moderna: la de la poesía como lenguaje fundamental. Samuel Ramos, traductor al español de este ensayo y prologuista, achaca - $\mathrm{o}$, al menos, le cabe la duda - a la concepción pesimista del hombre la atribución de la poesía y el arte a instancias divinas, que tratarían de compensar la finitud de lo humano. No creo que sea esa la razón, precisamente en quien repudia la concepción dogmática de la verdad por esa misma causa: ser un acto divino impuesto a los mortales. Lo cierto es que lo mundano es incapaz de expresar la verdad y, en cambio, la poesía - tal como la entiende Heidegger, casi sería más correcto decir lo literario (Dichtung) - ilumina el ente y lo oculta, dándonos la verdad. Una verdad que procede de la nada, pues no puede proceder de lo existente y habitual.

La verdad como alumbramiento y ocultación del ente acontece al poetizarse. Todo arte es como dejar acontecer el advenimiento de la verdad del ente en cuanto tal, y por lo mismo es en esencia Poesía $(1952,110)$.

Puede decirse que semejante concepción de la Poesía es, cuando menos, paradójica, pero no es justa la crítica de S. Ramos. La Poesía va esencialmente ligada al lenguaje - de ahí que Heidegger utilice el termino Dichtung, en vez de Poesie. 
Donde no existe ningún habla como en el ser de la piedra, la planta y el animal tampoco existe ninguna potencia del ente y en consecuencia tampoco de la no-existencia y de lo vacío $(1952,113)$.

Pero esta reivindicación del lenguaje como actividad inteligente va más allá. Comparte con los estructuralistas esa preeminencia del lenguaje sobre los demás sistemas referenciales. Heidegger complementa la función comunicativa del lenguaje con una función fundacional o primordial: «el lenguaje es el que lleva primero el ente como ente a lo manifiesto» (1952, 112). Sus esfuerzos van dirigidos a definir esa función fundacional: "proyectar la luz,» «descargar algo yacente», «proclamar lo abierto en la desgarradura de la forma», etc. Y lo curioso es que parece no situar esa operación «proyectante» en el ámbito de lo puramente metafísico, sino en un ámbito puramente histórico:

En tal decir se acuñan de antemano los conceptos de la esencia de un pueblo histórico, es decir, la pertenencia de este a la historia universal $(1952,113)$.

Esta presencia de lo histórico ligado a las esencias de un pueblo resulta, cuando menos, sospechosa de servir a las propensiones totalitarias del Heidegger de los años 30. Pero no me interesan tanto las servidumbres del pensamiento heideggeriano como sus alternativas paradójicas y estamos llegando al desenlace paradójico de su concepción de la Poesía. En efecto, no se trata tanto de que la Poesía haga brillar la verdad del ente, como que «el lenguaje mismo es Poesía en sentido esencial» $(1952,114)$;

el habla no es Poesía porque es la poesía primordial, sino que la poesía acontece en el habla porque esta guarda la esencia originaria de la Poesía (1952, 114).

¿Cuál es, pues, la diferencia entre lenguaje y Poesía? Pues parecen ser diferentes grados de alcanzar el alumbramiento del ente. Mientras que el lenguaje alumbra el ente inadvertidamente, la Poesía pone plena conciencia en ello. De ahí que Heidegger se extasíe leyendo cómo Hölderlin pone nombres a las cosas - cosa que después han hecho muchos otros poetas, entre ellos Juan Ramón Jiménez. Ese ingenuo juego adámico representaría para Heidegger la suma conciencia del alumbramiento de la verdad estética. Blanchot le dará a este asunto un espectacular giro retórico al asegurar que nombrar es aniquilar:

Dios había creado a los seres, pero el hombre hubo de aniquilarlos. Entonces cobraron sentido para él, y a su vez los creó a partir de esa muerte en la que habían desaparecido (Blanchot 1981, 44)

Mi lenguaje no mata a nadie. Mas si esta mujer no fuera en realidad capaz de morir, si a cada momento de su vida no estuviera amenazada de muerte, vinculada y unida a ella por un vínculo de esencia, yo no podría realizar esa negación ideal, ese asesinato diferido que es mi lenguaje. 
Por tanto, es precisamente exacto decir: cuando hablo, la muerte habla en mí (Blanchot 1981, 45).

Hölderlin frente a Hegel, Heidegger frente a Blanchot. El lenguaje hace patente la obra o el lenguaje es la voz de la muerte. En el ensayo «Hölderlin y la esencia de la poesía», Heidegger parece resolver esa paradoja: «el lenguaje es el más inocente de los bienes» y «el lenguaje es el más peligroso de los bienes». El habla existe para hacer patente al ente como tal y protegerlo, pero, al mismo tiempo crea «el lugar abierto de la amenaza y del error del ser y la posibilidad de perder el ser» $(1938,131)$. Solo hay mundo donde hay discurso, pero también caída y extravío. Esa es la más alta posibilidad del hombre.

\section{VERDAD Y BELLEZA}

«La esencia de la poesía es la instauración de la verdad» $(1952,114)$. De Waelhens se apresura a añadir que no se trata de una verdad absoluta. Efectivamente, sería extraño encontrar en Heidegger una concepción dogmática de la verdad. Es decir, que la cuestión no es tanto afirmar que no se trata de una verdad absoluta, sino preguntarnos qué tipo de verdad es la que instaura la contemplación estética - porque sólo es real la instauración en la contemplación que siempre será futura y concreta- esto es, un grupo humano histórico. La respuesta de Heidegger es la siguiente:

El proyecto poetizante que tiene la verdad es la patentización de aquello en lo que el existente está ya proyectado como histórico. Esto es la tierra y para un pueblo histórico su tierra, el fundamento autoocultante en donde descansa con todo lo que, aun oculto para él mismo, él es $(1952,115)$.

Hay en esta respuesta dos dimensiones que deben hacernos reflexionar: la historia y la tierra. El primer asunto me parece escasamente problemático: lo que capta el arte es la dimensión histórica de un hecho o acontecimiento. Esto ha sido explicado de muy diversas formas - coincidentes en lo sustancial - por distintos teóricos. Lotman ha llamado la atención sobre la capacidad del arte de actuar como memoria y Dilthey o Lukács insistieron en la capacidad del arte de captar lo típico, lo esencial, y sólo esto puede alcanzar el status de histórico. En realidad esta reivindicación de lo histórico viene ya dada desde el momento en que encuentra que el destino del arte es mostrar la verdad. Ese carácter esencial no puede desligarse de la historia. En cambio, el segundo elemento de aquella respuesta me resulta paradójico e, incluso, incongruente. En mi opinión no es la tierra - la tierra de un pueblo- lo que se patentiza de lo existente proyectándolo como histórico, sino el mundo, su mundo. El mismo Heidegger parece rectificar de inmediato, cuando a renglón seguido de las líneas citadas más arriba añade: 
Pero es su mundo el que impera por la relación del existente con la desocultación del ser $(1952,115)$.

He aquí otra de las paradojas en que se resuelve el pensamiento heideggeriano. Es claro que la tierra no puede tener una dimensión histórica y que la que realmente la posee es el mundo. Es más, —siguiendo la metáfora heideggeriana - lo que aporta la tierra a la obra es el elemento de intemporalidad, la proyección perenne hacia la contemplación futura. Encadena el mundo histórico en los límites materiales de la obra para hacerlo eternamente patente. En cambio, también resulta claro por qué Heidegger suplanta el mundo por la tierra a la hora de establecer la hegemonía de los componentes de la obra. Lo esencial de la obra literaria (de la Poesía, así con mayúscula en el lenguaje heideggeriano) es el lenguaje - su tierra. Unas páginas más adelante ya recordaba ese axioma con el que Heidegger establece la relación Poesía-Lenguaje:

\footnotetext{
el habla no es poesía porque es la poesía primordial, sino que la poesía acontece en el habla porque esta guarda la esencia originaria de la Poesía $(1952,114)$.
}

Esto es, la tierra de las tierras, el lenguaje, es ya el arte inadvertido, inconsciente. El lenguaje es el soplo divino que hace del hombre algo más que un hombre. Estas imágenes pueden resultar atrayentes, pero desde el punto de vista de la soberanía de las ideas resultan tautológicas y paradójicas. Volvamos a la pregunta originaria sobre el carácter de la verdad estética. Resulta que la obra estética es tanto más verdad cuanto más se acerca al lenguaje. Por eso la Poesía es más artística y más verdadera que la arquitectura y la escultura que «siempre acontecen ya y sólo en lo patente del decir y del nombrar» $(1952,114)$. Y que su dimensión histórica «sólo es el destino mismo» ya contenido en lo existente (Dasein). Así que, más allá de la crítica a las verdades absolutas, puesta de manifiesto por la reivindicación heideggeriana de la verdad como acontecimiento - reivindicación, por lo demás, justísima - tenemos que, en definitiva, el acontecimiento heideggeriano se queda en mera tautología, eso sí magníficamente envuelto en paradojas. Veamos la última muestra:

La proyección poética sale de la nada, en cuanto a que nunca toma su ofrenda de lo corriente y ya ahora ocurrido. Sin embargo, no sale jamás de la nada debido a que lo proyectado por ella sólo es el destino mismo ya previamente contenido del existente histórico mismo $(1952,116)$.

$\mathrm{Y}$ tras esta brillante - y estéril - paradoja podemos pasar a la última cuestión: la muerte del arte. 


\section{LA MUERTE DEL ARTE}

No abordaré esta cuestión aquí por extenso, o al menos con toda la extensión que merece - tarea que queda para una próxima entrega. Sólo me interesa la conexión de esta idea hegeliana con esta empresa heideggeriana. A la pregunta:

¿Es todavía el arte una manera esencial y necesaria en que acontece la verdad decisiva para nuestra existencia histórica o ya no lo es? $(1952,121)$

no responde Heidegger de forma categórica. Simplemente se limita a afirmar las condiciones en que puede contestarse afirmativa o negativamente. Negativamente todavía no puede responderse, porque «en el modo como el ente es real para el mundo occidental se oculta una coincidencia peculiar de la belleza con la verdad» $(1952,122)$. Traza Heidegger una cadena que muestra como todavía hoy se da una conexión con los fundamentos griegos de la cultura occidental: eidós, idea, morfé, (hylé), energeia, actualitas, realidad, objetividad y vivencia. Esta continuidad impide la respuesta negativa, pero también impide la afirmación.

Todo es vivencia. Sin embargo, quizá es la vivencia el elemento en que muere el arte. La muerte sucede tan lentamente que necesita algunas centurias $(1952,120)$.

Luego todo es cuestión de tiempo. Más o menos pronto podremos dar el arte por liquidado. De hecho, Heidegger parece intuir ya «un tiempo en que el arte grande junto con su esencia se ha retirado del hombre» $(1952,120)$. Pero conviene no perder de vista que nos está hablando de un arte que debe expresar la vivencia y de que es esto lo que muere en el arte, la vivencia. Vattimo ha apuntado la posibilidad de que con ese arte al que se le muere la vivencia perezca también su estética, la estética de la tradición. Y añade que esta estética podría no ser ni el único sistema conceptual posible, ni un conjunto de nociones falsas «por estar privadas de referente en la experiencia» $(1985,56)$. Pues bien, me interesa especialmente el primer término de esa disyuntiva: la estética de la tradición no es el único sistema conceptual posible, por la razón - bastante evidente- de que existen otras estéticas alternativas a la estética de la tradición y que ésta no es la única forma posible del arte. Esas estéticas alternativas no buscan la vivencia. Esas estéticas alternativas se fundan en otro modo de concebir el ser-obra que no es el de la vivencia, sino su negación, la insuficiencia de la vivencia, de la identidad, negación que se suele expresar mediante la risa. No entraré ahora en esta cuestión. Simplemente señalaré que Hegel, que es el padre de esta polémica, sólo reconoció la estética de la tradición y de la identidad - a pesar de dedicar excelentes páginas a una teoría de 
lo cómico. La Estética, en cuanto estética literaria, sólo reconoce los géneros canónicos tradicionales: la épica, la lírica y el drama. Y desconoce los géneros anticanónicos, o mejor dicho, el único género sin canon: la novela. Una estética basada en la novela es, como ha demostrado la obra de M. Bajtín, una estética del futuro, capaz de superar las antinomias agónicas de la estética de la tradición, la estética de la identidad.

En síntesis, puede decirse que la obra de Heidegger representa un paso decidido hacia la superación de la negación de la estética, que caracteriza el pensamiento moderno. Pero también debe añadirse que ese paso resulta insuficiente, pues no se funda en una crítica del discurso teórico que ocupa el lugar de la estética en nuestra era ni conecta con las más grandes líneas de pensamiento estético que ha dado la historia, sino que trata de ser un desarrollo de una concepción general pero limitada del ser en el tiempo.

\section{REFERENCIAS BIBLIOGRÁFICAS}

Blanchot, M. (1981), De Kafka à Kafka. París: Gallimard. Trad. esp. De Kafka a Kafka, Méjico: FCE, 1991.

De Waelhens, A. (1942), La philosophie de Martin Heidegger, 5. a ed. París: Publications Universitaires de Louvain, 1967.

HeIDEGGER, M. (1937), «Hölderlin und das Wesen der Dichtung». Citado por la trad. esp. «Hölderlin y la esencia de la poesía», Arte y Poesía, Méjico: FCE, 1988, $125-148$.

- (1952), «Der Ursprung des Kunstwerkes». Citado por la trad. esp. «El origen de la obra de arte», Arte y poesía, Méjico: FCE, 1988, 35-123.

MAGLIOLA, R. (1983), «Eigentlichkeit and Einfall: the Heideggerian Return 'To Things Themselves'». Literary Criticism and Philosophy. Yearbook of Compartive Criticism. Vol X, Ed. J. P. Strelka. University Park y Londres: The Pennsylvania State U. P. 111-131.

VAtтimo, G. (1985), La fine della modernità. Trad. esp. El fin de la modernidad, 2. ${ }^{\mathrm{a}} \mathrm{ed}$, Barcelona: Gedisa. 1987. 
LUIS BELTRÁN ALMERÍA

\title{
RESUMEN
}

¿Es posible la estética literaria? (Nota sobre la ceoncepción de Heidegger), por Luis Beltrán Almería.

El programa filosófico de Heidegger encuentra un problema en la forma de entender el ser estético en el tiempo. Heidegger propone cinco conceptos para entender esta forma de ser más allá del ser cosa: el creador, el contemplador, la tierra, el mundo y la forma. Este planteamiento supone un avance hacia la estética, pero tiene también sus limitaciones.

Palabras clave: Estética, objeto estético, forma estética, material y contenido.

\begin{abstract}
The philosophy of Heidegger finds a problem in the understanding of aesthetic being. Heidegger proposes five concepts to understand the aesthetics being: creator, watcher, earth, world and form. Such approach is itself an advance toward aesthetics. However this view has also its limitations.
\end{abstract}

Key words: Aesthetics, aesthetic object, aesthetic form, material, content. 